\title{
Difference in the metabolism of vitamin $K$ between liver and bone in vitamin K-deficient rats
}

\author{
Toshiro Sato ${ }^{1}$, Yutaka Ohtani ${ }^{1}$, Yoko Yamada ${ }^{1}$, Sanshiroh Saitoh ${ }^{2}$ and Hiroshi Harada ${ }^{3}$ \\ ${ }^{1}$ Chemicals Research Laboratories, Honen Corporation, Asaba-cho, Iwata-gun, Shizuoka 437-1111, Japan \\ ${ }^{2}$ Food Research Laboratories, Honen Corporation, Shimizu City, Shizuoka 424-0824, Japan \\ ${ }^{3}$ Department of Nutritional Science, Faculty of Applied Biological Science, Tokyo University of Agriculture, 1-1-1 \\ Sakuragaoka, Setagaya-ku, Tokyo 156-8502, Japan
}

(Received 6 February 2001 - Revised 5 November 2001 - Accepted 28 November 2001)

\begin{abstract}
The difference between vitamin $\mathrm{K}$ metabolism in the liver and that in the bone of vitamin $\mathrm{K}$-deficient rats was examined. After $17 \mathrm{~d}$ administration of vitamin K-deficient food, vitamin $\mathrm{K}$ in the liver was almost depleted, and prothrombin time (PT) was prolonged. Serum total osteocalcin level was slightly decreased by vitamin K deficiency, whereas serum undercarboxylated osteocalcin level did not change. The level of menaquinone (MK)-4 as well as that of phylloquinone was decreased, but approximately $40 \%$ of the initial level still existed in the femur after the $17 \mathrm{~d}$ period. A single-dose administration of vitamin $\mathrm{K}(250 \mathrm{nmol} / \mathrm{kg}$ body weight $)$ markedly increased vitamin $\mathrm{K}$ level in the liver but not in the femur. These results suggest that the turnover of vitamin $\mathrm{K}$ in the bone is slower than that in the liver, and bone metabolism may be little affected by the short period of intake of vitamin K-deficient food. However, intake of a larger amount of vitamin $\mathrm{K}$ is required for its accumulation in the bone than in the liver. Furthermore, the counteracting effect of MK-7 on prolonged PT in vitamin K-deficient rats was found to be higher than phylloquinone or MK-4.
\end{abstract}

Menaquinone: Phylloquinone: Vitamin K: Coagulation: Osteocalcin

Vitamin $\mathrm{K}$ is a cofactor required for the post-translational conversion of glutamic acid residues of specific proteins into $\gamma$-carboxyglutamic acid (Gla) to form Gla-containing proteins via $\gamma$-glutamylcarboxylase (Shearer, 1990). A number of blood coagulation factors including coagulation factors II (prothrombin), VII, IX and X are Gla-containing proteins, and are synthesized in the liver. Osteocalcin (OC), a bone-specific protein synthesized by osteoblasts, is also a Gla-containing protein. Noncarboxylated or undercarboxylated (uc) OC cannot bind to hydroxyapatite in mineralized tissues (Price, 1985). The nutritional requirement of vitamin $\mathrm{K}$ for the complete $\gamma$-carboxylation of $\mathrm{OC}$ is thought to be higher than that for the maintenance of normal blood coagulation in human subjects (Booth \& Suttie, 1998). Haffa et al. (2000) have shown that a low intake of vitamin $\mathrm{K}$ for $80 \mathrm{~d}$ increased in serum ucOC level but did not affect prothrombin time (PT) in rats.

There are two naturally occurring forms of vitamin $\mathrm{K}$ : phylloquinone $\left(\mathrm{K}_{1}\right)$ and menaquinone $(\mathrm{MK}) . \quad \mathrm{K}_{1}$ is synthesized by plants and is present in large amounts in various green vegetables, which are the major source of dietary vitamin K (Booth \& Suttie, 1998). MK has a variable side-chain length of four to thirteen isoprene units. They are referred to as MK- $n$, where $n$ denotes the number of isoprenoid residues. MK- $n$ are bacterial products that are found in fermented foods (Sakano et al. 1988, Hirauchi et al. 1989), as well as in intestinal flora in the colon (Collins \& Jones, 1981; Conly \& Stein, 1992). The extent to which MK- $n$ derived from intestinal bacteria contribute to the daily requirement of vitamin $\mathrm{K}$ remains a matter of debate at the present time (Uchida et al. 1986; Conly \& Stein, 1992; Suttie, 1995). In addition, in rats coprophagy is a rich dietary source of MK- $n$ because faeces contain substantial amounts of MK- $n$ (Vermeer et al. 1995). Whether hepatic MK- $n$ in the rat is derived from direct intestinal absorption or by coprophagy is also still not known. Mathers et al. (1990) reported that a white rice-based diet reduced hepatic $K_{1}$ and longer-chain MK levels. They showed that the lowfibre content of the diet resulted in caecal metabolism

Abbreviations: APTT, activated partial thromboplastin time; Gla, $\gamma$-carboxyglutamic acid; $\mathrm{K}_{1}$, phylloquinone (vitamin $\mathrm{K}_{1}$ ); MK, menaquinone (vitamin

$\mathrm{K}_{2}$ ); OC, osteocalcin; PT, prothrombin time; uc, undercarboxylated.

* Corresponding author: Dr T. Sato, fax +8153823 6772, email tosato@ honen.co.jp 
including reduced number of MK-producing bacterial species in the intestine. Groenen-van Dooren et al. (1995) developed an experimental animal model that exhibits severe vitamin $\mathrm{K}$ deficiency, in which rats equipped with anal cups to prevent coprophagy are fed vitamin K-deficient white-rice diet. In the present study, using the model of Groenen-van Dooren et al. (1995), comparative tissue measurement of $\mathrm{K}_{1}$ and MK- $n$ in liver and bone was carried out in vitamin K-deficient rats. Then, the effect of acute vitamin K deficiency on blood coagulation and serum total OC or ucOC level was examined. Furthermore, the relative effects of $\mathrm{K}_{1}$, MK-4 and MK-7 on blood coagulation and serum OC levels were investigated.

\section{Materials and methods}

\section{Chemicals}

$\mathrm{K}_{1}$ and MK-4 were purchased from Wako Pure Chemicals Industries (Osaka, Japan). MK-6, -7 and -8 were purified from Bacillus subtilis in our laboratory (Sato et al. 2001). 2',3'-Dihydrophylloquinone was prepared in our laboratory. $\mathrm{K}_{1}$, MK-4 and MK-7, dissolved in ethanol solution $(995 \mathrm{ml} / \mathrm{l})$ to make a concentration of $2 \mathrm{mM}$, were suspended in gum arabic $(50 \mathrm{~g} / \mathrm{l})$ while adjusting the final concentration of each K-vitamer to 40 or $200 \mathrm{nmol} / \mathrm{ml}$. Rat OC was purchased from Biomedical Technologies Inc. (Stoughton, MA, USA). Hydroxyapatite and other chemicals from Wako Pure Chemicals Industries were of reagent grade. Warfarin sodium was purchased from Sigma (St Louis, MO, USA).

\section{Animals and diet}

The study was conducted in accordance with current legislation on animal experimentation in Japan. Male SpragueDawley rats (Charles River Co., Yokohama, Japan) were housed in individual stainless-steel, wire-bottomed cages. They were kept in an air-conditioned room at $24^{\circ} \mathrm{C}$ with a $12 \mathrm{~h}$ light-dark cycle. They were 11-weeks-old when the experiment started. The rats had free access to the AIN93 formula diet (Oriental Yeast, Tokyo, Japan) and distilled water for 1 week. Then, the rats were fed a radiated $(50 \mathrm{kGy})$ vitamin K-deficient diet (Oriental Yeast) based on the formula of Groenen-van Dooren et al. (1993) that contained $(\mathrm{g} / \mathrm{kg})$ : vitamin-free casein 210, synthetic methionine 1.5 , cooked and dried white rice 500, sucrose 225, vitamin-K-free corn oil 28.5, minerals 25 , vitamins (without vitamin $\mathrm{K}$ ). The total amount of vitamin $\mathrm{K}$ was $<1 \mu \mathrm{g} / \mathrm{kg}$ diet. Rats fed the diet to which $\mathrm{K}_{1}$ was added $(1.0 \mathrm{mg} / \mathrm{kg}$ diet $)$ were used as a normal control. All rats were equipped with anal cups to prevent coprophagy throughout the experiment. After $14 \mathrm{~d}$ of vitamin $\mathrm{K}$ deficiency, a single dose of a K-vitamer, $\mathrm{K}_{1}, \mathrm{MK}-4$ or MK-7, was orally administered using a catheter. Rats that did not receive vitamin $\mathrm{K}$ throughout this study were used as K-deficient control. Blood $(0.9 \mathrm{ml})$ was collected from a vein under clavicle using a syringe before the administration of vitamin $\mathrm{K}$ (=initial), and at $6,24,48$, and $72 \mathrm{~h}$ after the administration. Then, $0.63 \mathrm{ml}$ of the blood was transferred to a test-tube containing $0.07 \mathrm{ml}$ sodium citrate $(38 \mathrm{~g} / \mathrm{l})$. The tube was centrifuged at $3000 \mathrm{rpm}$ at $4^{\circ} \mathrm{C}$ for $15 \mathrm{~min}$ and the plasma obtained was used for the examination of coagulation. Another portion of the blood collected was centrifuged at $3000 \mathrm{rpm}$ at $4^{\circ} \mathrm{C}$ for $15 \mathrm{~min}$ and the resultant serum was used for the determination of serum OC level.

In order to analyse the change in concentration of vitamin $\mathrm{K}$ after administration, some animals were killed under light anaesthesia with diethyl ether, and the blood, liver and femur were removed immediately. Blood $(1.8 \mathrm{ml})$ was collected from the abdominal aorta using a syringe containing $0.2 \mathrm{ml}$ sodium citrate $(38 \mathrm{~g} / \mathrm{l})$. The blood collected was centrifuged at $3000 \mathrm{rpm}$ for $15 \mathrm{~min}$ and a plasma sample was obtained. The liver was washed with saline to remove blood. The concentrations of vitamin $\mathrm{K}$ in the plasma, liver and femur were determined as described later.

\section{Chemical analyses}

PT and activated partial thromboplastin time (APTT) were determined to study blood coagulation using plasma by Thromboplastin C Plus and Symex CA-500 (Symex Co., Kobe, Japan) respectively. Before starting an experiment, blood was collected from each rat to determine the initial values.

Total serum OC level was determined by ELISA using a commercially available kit (Biomedical Technologies Inc.). We prepared thermally decarboxylated OC according to the method of Poser \& Price (1978) and confirmed that the kit detected decarboxylated OC with the same sensitivity as that for $\gamma$-carboxylated OC detection.

ucOC was measured using the method that is based on the difference in affinity between carboxylated OC and decarboxylated OC for hydroxyapatite (Merle \& Delmas, 1990). Briefly, $50 \mu \mathrm{l}$ samples were incubated with $3 \mathrm{mg}$ hydroxyapatite suspended in $30 \mu \mathrm{l} 10 \mathrm{~mm}$-borate buffer (pH 7.3) containing $2 \mathrm{mM}^{-} \mathrm{CaCl}_{2}$ in an Eppendorf tube at $4^{\circ} \mathrm{C}$ for $4 \mathrm{~h}$ and then centrifuged. This concentration of hydroxyapatite was chosen because it gave the best discrimination between the hydroxyapatite-binding ability of $\gamma$-carboxylated OC and that of thermally decarboxylated OC. To confirm the adequacy of this assay, three rats were treated with sodium warfarin $(1.5 \mathrm{mg} / \mathrm{kg}$ diet $)$ for $7 \mathrm{~d}$ and their serum ucOC and total OC levels were measured. The percentage of ucOC in total OC was determined to be $69-87 \%$, indicating that the assay is sufficiently sensitive to detect an increase in ucOC.

\section{Determination of concentration of vitamin $K$}

$\mathrm{K}_{1}$ and MK- $n$ concentrations in the plasma, liver and femur were measured by HPLC as follows. Plasma $(500 \mu \mathrm{l})$, 2-propanol $(650 \mu \mathrm{l})$ and $1.3 \mathrm{ml} n$-hexane containing $5 \mathrm{ng}$ $2^{\prime}, 3^{\prime}$-dihydrophylloquinone as an internal standard were added, mixed vigorously, and centrifuged. A portion of the $n$-hexane layer $(1 \mathrm{ml})$ was removed and evaporated. To the residue obtained, $200 \mu \mathrm{l} 2$-propanol was added and a $50 \mu \mathrm{l}$ aliquot was injected into the HPLC column. Femurs were cleaned of soft tissue and marrow, and added to $5 \mathrm{ml}$ water, $20 \mathrm{ml}$ 2-propanal and $20 \mathrm{ml}$ 
$n$-hexane containing $10 \mathrm{ng} 2^{\prime}, 3^{\prime}$-dihydrophylloquinone. Samples of livers $(1 \mathrm{~g})$ were added to $3 \mathrm{ml}$ water, $20 \mathrm{ml}$ 2-propanol and $20 \mathrm{ml} n$-hexane containing $2^{\prime}, 3^{\prime}$-dihydrophylloquinone (10 ng). They were homogenized using a blender for $2 \mathrm{~min}$ and then centrifuged. The $n$-hexane layer was isolated and dried. The resultant pellet was dissolved in $n$-hexane, and then eluted through Sep-Pak silica (Milford, MA, USA) using toluene-hexane $(3: 2, \mathrm{v} / \mathrm{v})$. The eluted samples were dried and dissolved in $n$-hexane. The samples were purified by HPLC using $n$-hexane-ether (30:1, v/v) and a silica-gel column (Unisil Q, $300 \times 16.7 \mathrm{~mm}$; GL Sciences, Tokyo, Japan), and elution was monitored at $253 \mathrm{~nm}$. The solvent was evaporated, and the samples were re-dissolved in 2-propanol and analysed by HPLC. HPLC evaluation was carried out using a Shimadzu LC-10A system equipped with a fluorescence detector. The sample was separated using an ODS column (L-column, $250 \mathrm{~mm} \times 4.6 \mathrm{~mm}$; Chemical Inspection and Testing Institute, Tokyo, Japan) and peaks were detected using a fluorescence detector after reduction by Pt black (Reduction column, $10 \times 4.6 \mathrm{~mm}$; Toa, Tokyo, Japan). Detection of vitamin $\mathrm{K}$ level was carried out at an excitation wavelength of $320 \mathrm{~nm}$ for serum and bone or $244 \mathrm{~nm}$ for liver; and an emission wavelength of $430 \mathrm{~nm}$. The mobile phase contained $200 \mathrm{ml} \mathrm{2-propanol}$ and $800 \mathrm{ml}$ methanol. The flow rate was $1.2 \mathrm{ml} / \mathrm{min}$. Detection limits of $\mathrm{K}_{1}$ and $\mathrm{MK}-n$ were $1.0 \mathrm{pmol} / \mathrm{ml}$ plasma or $/ \mathrm{g}$ liver or femur.

\section{Statistical analysis}

All data were expressed as mean values with their standard errors. Differences between groups were compared using Dunnet's multiple comparison tests, and were considered to be significant when $P$ values were $<0.05$.

\section{Results}

\section{Effect of vitamin $K$ deficiency of blood coagulation and serum osteocalcin}

Rats equipped with anal cups were given the vitamin K-deficient diet ad libitum throughout this study. On day 10 or 17 after the experiment was started, PT, APTT, serum total OC level and serum ucOC level (ucOC:total OC) were determined (Table 1). PT and APTT were prolonged in vitamin K-deficient rats, but not in the normal control group fed $1 \mathrm{mg} \mathrm{K}_{1} / \mathrm{kg}$ diet. Vitamin $\mathrm{K}$ deficiency caused a slight decrease in the total OC level. However, the serum ucOC level did not change after the $17 \mathrm{~d}$ administration of vitamin K-deficient diet (Table 1).

Levels of $\mathrm{K}_{1}$ and MK- $n$ in the plasma, the liver and the femur before or after $17 \mathrm{~d}$ administration of the vitamin K-deficient diet or the same diet supplemented with $1 \mathrm{mg} \mathrm{K}_{1} / \mathrm{kg}$ diet were determined by HPLC (Table 2 ). $\mathrm{K}_{1}$ and a small amount of MK- $n$ were detected in the liver of the normal control group, while both $\mathrm{K}_{1}$ and MK- $n$ were almost depleted in the liver of the vitamin K-deficient group. In the femur, more $\mathrm{MK}-4$ than $\mathrm{K}_{1}$ existed on day 0 or day 17 in both groups. The levels of MK-4 and $\mathrm{K}_{1}$ were decreased in the femur of vitamin K-deficient rats, although approximately $40 \%$ of the initial values (day 0) remained.

\section{Changes in vitamin $K$ levels in plasma, liver and bone after administration of $K$-vitamers}

Vitamin K-deficient rats were treated with a single dose of $\mathrm{K}_{1}$, MK-4 or MK-7 (250 nmol/kg body weight). Three samples each of blood, liver and femur were collected from three rats per time point, before the experiment and at 6 and $24 \mathrm{~h}$ after administration of vitamin $\mathrm{K}$, and five samples were collected from five different rats at $72 \mathrm{~h}$. Then, the levels of vitamin $\mathrm{K}$ were determined (Fig. 1). The levels of the three $\mathrm{K}$ vitamers, $\mathrm{K}_{1}, \mathrm{MK}-4$ and MK-7, in the plasma at $6 \mathrm{~h}$ were almost the same. In the liver, all $\mathrm{K}$ vitamers were detected throughout the experiment in each group, while the turnover of MK-7 was slower than that of $K_{1}$ or MK-4. No significant increase in vitamin $\mathrm{K}$ was found in the femur for all groups. The vitamin $\mathrm{K}$ level in the femurs of rats that received administered a single dose of K-vitamer ( $250 \mathrm{nmol} / \mathrm{kg}$ body weight) was the same as that of the vitamin K-deficient control group (Table 2 and Fig. 1).

\section{Effect of $K$-vitamers on blood coagulation in vitamin K-deficient rats}

PT was measured to study blood coagulation in vitamin $\mathrm{K}$-deficient rats. It was found to be significantly prolonged after $14 \mathrm{~d}$ vitamin $\mathrm{K}$ deficiency (Table 1). The effects of

Table 1. Effects of vitamin $\mathrm{K}$ deficiency on blood coagulation and serum osteocalcin in rats $\dagger$

(Mean values with their standard errors for five rats per group)

\begin{tabular}{|c|c|c|c|c|c|c|c|c|c|c|c|c|}
\hline & \multicolumn{4}{|c|}{ Initial } & \multicolumn{4}{|c|}{$10 d$} & \multicolumn{4}{|c|}{$17 d$} \\
\hline & \multicolumn{2}{|c|}{ Control } & \multicolumn{2}{|c|}{ K-deficient } & \multicolumn{2}{|c|}{ Control } & \multicolumn{2}{|c|}{ K-deficient } & \multicolumn{2}{|c|}{ Control } & \multicolumn{2}{|c|}{ K-deficient } \\
\hline & Mean & SEM & Mean & SEM & Mean & SEM & Mean & SEM & Mean & SEM & Mean & SEM \\
\hline PT (s) & $16 \cdot 6$ & 0.9 & $16 \cdot 8$ & 0.3 & $16 \cdot 4$ & 0.4 & $19 \cdot 7$ & $1 \cdot 8$ & $16 \cdot 5$ & 0.3 & $35 \cdot 0^{* *}$ & $4 \cdot 2$ \\
\hline APTT (s) & $15 \cdot 5$ & 1.2 & $15 \cdot 3$ & 0.8 & $15 \cdot 5$ & 1.2 & $25 \cdot 4^{*}$ & 2.5 & $17 \cdot 3$ & 0.6 & $41.4^{\star *}$ & 4.4 \\
\hline Total OC (ng/ml) & $66 \cdot 0$ & $3 \cdot 1$ & 63.9 & 1.8 & 55.5 & $4 \cdot 2$ & 44.4 & 2.5 & $64 \cdot 2$ & $5 \cdot 2$ & 52.5 & $4 \cdot 7$ \\
\hline ucOC:Total OC (\%) & $14 \cdot 1$ & 1.0 & $13 \cdot 0$ & 1.0 & $15 \cdot 2$ & $1 \cdot 2$ & $12 \cdot 9$ & 0.9 & $15 \cdot 5$ & 0.8 & $12 \cdot 7$ & $1 \cdot 1$ \\
\hline
\end{tabular}

PT, prothrombin time; APTT, activated partial thromboplastin time; OC, osteocalcin; uc, undercarboxylated.

Mean values were significantly different from those of the control group: ${ }^{\star} P<0.05,{ }^{* \star} P<0.01$.

†For details of diets and procedures, see p. 308. 
Table 2. Concentration of vitamin $\mathrm{K}$ in plasma, liver and femur before or after $17 \mathrm{~d}$ administration of experimental diet supplemented with $1 \mathrm{mg}$ phylloquinone/kg diet (control) or vitamin K-deficient diet*

(Mean values with their standard errors for five rats per group)

\begin{tabular}{|c|c|c|c|c|c|c|c|c|c|c|c|c|c|c|}
\hline & \multicolumn{14}{|c|}{ Concentration of vitamin $\mathrm{K}$} \\
\hline & \multicolumn{2}{|c|}{$\mathrm{K}_{1}$} & \multicolumn{2}{|c|}{ MK-4 } & \multicolumn{2}{|c|}{ MK-5 } & \multicolumn{2}{|c|}{ MK-6 } & \multicolumn{2}{|c|}{ MK-7 } & \multicolumn{2}{|c|}{ MK-8 } & \multicolumn{2}{|c|}{ MK-9 } \\
\hline & Mean & SEM & Mean & SEM & Mean & SEM & Mean & SEM & Mean & SEM & Mean & SEM & Mean & SEM \\
\hline \multicolumn{15}{|c|}{ Serum (pmol/ml) } \\
\hline Initial & 10 & 0.8 & 0.7 & 0.5 & & & & & 0.7 & 0.3 & & & & \\
\hline Control & 11 & 1.4 & 0.7 & 0.3 & & & & & & & & & & \\
\hline K-deficient & \multicolumn{2}{|c|}{ ND } & \multicolumn{2}{|c|}{ ND } & & & \multicolumn{2}{|c|}{ ND } & & & \multicolumn{2}{|c|}{ ND } & \multicolumn{2}{|c|}{ ND } \\
\hline \multicolumn{15}{|l|}{ Liver (pmol/g) } \\
\hline Initial & 66 & $5 \cdot 7$ & $3 \cdot 2$ & 1.6 & & & $8 \cdot 9$ & 1.5 & 21 & $6 \cdot 8$ & $6 \cdot 2$ & $4 \cdot 7$ & $7 \cdot 3$ & $5 \cdot 2$ \\
\hline Control & 70 & $6 \cdot 1$ & 1.6 & 0.5 & & & \multirow{2}{*}{\multicolumn{2}{|c|}{$\begin{array}{l}\text { ND } \\
\text { ND }\end{array}$}} & 3.3 & 1.8 & 0.7 & 0.5 & 0.2 & 0.2 \\
\hline K-deficient & 2.5 & 1.3 & \multicolumn{2}{|c|}{ ND } & & & & & 2.4 & 1.5 & \multicolumn{2}{|c|}{ ND } & \multicolumn{2}{|c|}{ ND } \\
\hline \multicolumn{15}{|l|}{ Bone $(\mathrm{pmol} / \mathrm{g})$} \\
\hline Initial & 33 & 1.9 & 67 & 3.2 & & & \multicolumn{2}{|c|}{ ND } & 0.7 & 0.3 & \multicolumn{2}{|c|}{ ND } & \multicolumn{2}{|c|}{ ND } \\
\hline Control & 29 & 1.2 & 59 & 1.3 & & & \multicolumn{2}{|c|}{ ND } & 0.5 & 0.2 & \multicolumn{2}{|c|}{ ND } & \multicolumn{2}{|c|}{ ND } \\
\hline K-deficient & 13 & 0.8 & 26 & 1.4 & & & \multicolumn{2}{|c|}{ ND } & 0.6 & 0.2 & \multicolumn{2}{|c|}{ ND } & \multicolumn{2}{|c|}{ ND } \\
\hline
\end{tabular}

$\mathrm{K}_{1}$, phylloquinone; MK, menaquinone; ND, not detected.

${ }^{*}$ For details of diets and procedures, see p. 308.

$\mathrm{K}_{1}$, MK-4 and MK-7 on blood coagulation were compared on a molar basis, $50 \mathrm{nmol} / \mathrm{kg}$ body weight, which was equivalent to $22.5\left(\mathrm{~K}_{1}\right), 22.2$ (MK-4) or 32.5 (MK-7) $\mu \mathrm{g} /$ $\mathrm{kg}$, and $250 \mathrm{nmol} / \mathrm{kg}$ body weight, which was equivalent to $112.5\left(\mathrm{~K}_{1}\right), 111.0(\mathrm{MK}-4)$ or $162.5(\mathrm{MK}-7) \mu \mathrm{g} / \mathrm{kg}$ (Fig. 2). On day 14, the 50 or $250 \mathrm{mmol}$ vitamin $\mathrm{K} / \mathrm{kg}$ body weight was administered to vitamin K-deficient rats $\left(\begin{array}{ll}t & 0) \text {. }\end{array}\right.$

Administration of vitamin $\mathrm{K}$ shortened the prolonged PT induced by vitamin $\mathrm{K}$ deficiency. These effects continued over $72 \mathrm{~h}$ in all groups that received K-vitamers $(250 \mathrm{nmol} / \mathrm{kg})$, whereas in the low-dose case $(50 \mathrm{nmol} /$ $\mathrm{kg}$ ), the effect of MK-7 lasted longer than that of $\mathrm{K}_{1}$ or MK-4.

The counteracting effects of a single dose of $\mathrm{K}_{1}$, MK-4 or MK-7 (50 or $250 \mathrm{nmol} / \mathrm{kg}$ body weight) on the prolonged APTT in vitamin K-deficient rats were also examined (results not shown). The effect of MK-7 on shortening APTT lasted longer than that of $\mathrm{K}_{1}$ or MK-4. The effect of MK-7 $(50 \mathrm{nmol} / \mathrm{kg})$ on APTT was greater than that of $\mathrm{K}_{1}(250 \mathrm{nmol} / \mathrm{kg})$ or MK-4 $(250 \mathrm{nmol} / \mathrm{kg})$.

\section{Effect of $K$-vitamers on osteocalcin in vitamin $K$-deficient rats}

Serum total OC level slightly decreased after 10 or $17 \mathrm{~d}$ of vitamin $\mathrm{K}$ deficiency (Table 1). The effect of K-vitamers $(250 \mathrm{nmol} / \mathrm{kg}$ body weight) on the level of serum total OC was examined (Fig. 3). A low dose of vitamin K $(50 \mathrm{nmol} / \mathrm{kg})$ had no effect on the serum total OC level (results not shown). Serum ucOC level was not elevated by $17 \mathrm{~d}$ of vitamin $\mathrm{K}$ deficiency (Table 1 ) and the administration of vitamin $\mathrm{K}(250 \mathrm{nmol} / \mathrm{kg}$ body weight $)$ did not affect serum ucOC level in all groups (results not shown).

\section{Discussion}

Many of the factors involved in blood coagulation are vitamin K-dependent Gla-containing proteins. With regard to blood coagulation, vitamin $\mathrm{K}$ deficiency is rare in adult man (Sokoll et al. 1997). Recent studies, however, revealed that the current daily intake of vitamin $\mathrm{K}$ is not sufficient to maximally $\gamma$-carboxylate OC. Low intake of vitamin $\mathrm{K}$ causes an increase in the serum ucOC level, which is correlated with hip-bone mineral density in elderly women (Szulc et al. 1994) and with hip fracture in elderly women (Szulc et al. 1993). Supplementation of K-vitamers, $K_{1}$ (Sokoll et al. 1997), MK-4 (Shiraki et al. 2000) and MK-7 (Tsukamoto et al. 2000), decreased serum ucOC level in human subjects. Furthermore, insufficient intake of vitamin $K_{1}(20 \mathrm{ng} / \mathrm{g}$ diet $)$ over an $80 \mathrm{~d}$ period caused an increase in serum ucOC level but did not affect PT in rats (Haffa et al. 2000). These observations have led to the conclusion that more vitamin $\mathrm{K}$ is necessary for the $\gamma$-carboxylation of OC than the amount required for the maintenance of plasma prothrombin levels (Booth \& Suttie, 1998). In contrast to these reports, however, we obtained an apparently conflicting result in the present study. An acute vitamin K deficiency for $14-17 \mathrm{~d}$ made blood coagulation abnormal, i.e. prolonged PT and APTT, without affecting serum ucOC level. $\mathrm{K}_{1}$ and MK- $n$ were almost depleted in the liver by the $17 \mathrm{~d}$ vitamin $\mathrm{K}$ deficiency, whereas $\mathrm{K}_{1}$ as well as MK-4 decreased by approximately $60 \%$ from their initial values and considerable amounts of $\mathrm{K}_{1}$ and MK-4 still remained in the femur. These results suggested that the turnover of vitamin $\mathrm{K}$ in the femur is slower than that in the liver.

In rats, coprophagy, as well as absorption of MK- $n$ produced in intestinal flora, is thought to be an important source of longer-chain MK- $n$, although the extent to which coprophagy or absorption contributes to the synthesis of various Gla-containing proteins remains under debate. In the present study, rats were fed a low-fibre diet based on white rice. The rice diet reduced hepatic longer-chain MK- $n$ by changing the number of MKproducing bacterial species in the intestine (Mathers et al. 1990). Barns \& Fiala (1959) reported that rats that were fed a vitamin K-deficient feed and whose coprophagy was 
(a)

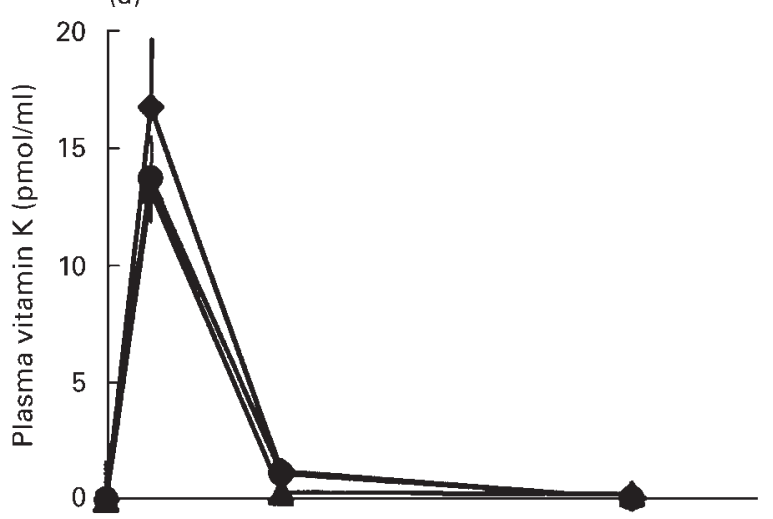

(b)

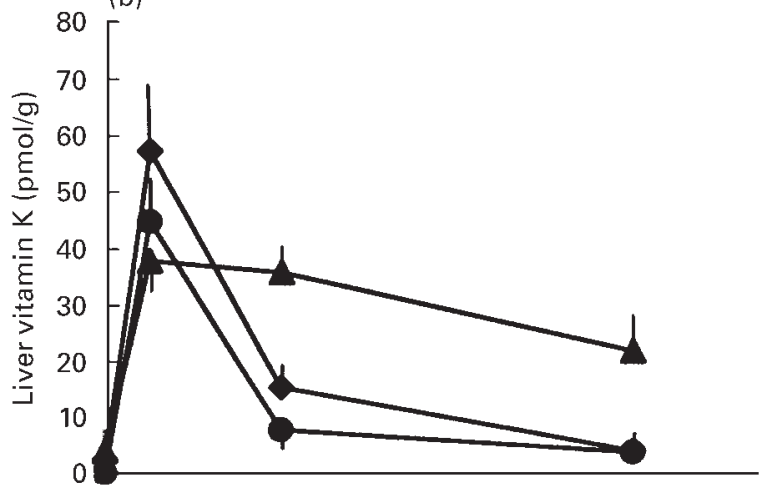

(c)

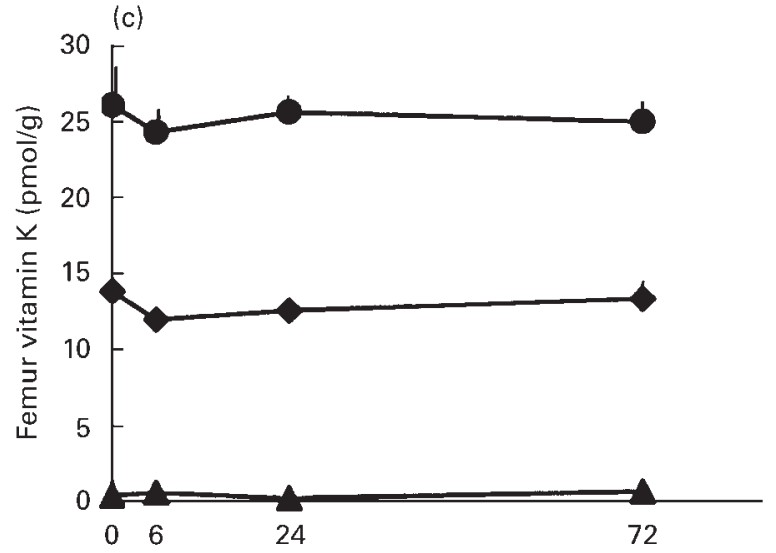

Fig. 1. Change in levels of vitamin $\mathrm{K}$ in (a) plasma, (b) liver and (c) femur of vitamin K-deficient rats after a single-dose administration of phylloquinone, $(\bullet)$ menaquinone $(\mathrm{MK})-4(\bullet)$ or MK-7 (४) $(250 \mathrm{nmol} / \mathrm{kg}$ body weight). For details of diets and procedures, see p. 308. Values are means for three rats at 0,6 and $24 \mathrm{~h}$ and five rats at $72 \mathrm{~h}$ with standard errors shown by vertical bars.

effectively prevented, developed hypoprothrombinaemia despite the presence of bacteria in their colon. In our present study, the feeding of the rice diet together with the vigorous prevention of coprophagy was expected to drastically reduce hepatic $\mathrm{K}_{1}$ and long-chain MK- $n$ levels. We found that longer K-vitamers were almost depleted and only low levels of MK-7 and $\mathrm{K}_{1}$ were detected after $17 \mathrm{~d}$ of vitamin $\mathrm{K}$ deficiency. On the other hand, the study of Haffa et al. (2000) did not use a low-fibre diet or any specific coprophagy-preventing apparatus. Therefore, it was thought that chronic insufficient $\mathrm{K}_{1}$ intake in their model could cause an increase in ucOC level, while the long-chain MK- $n$ derived from coprophagy protects $\gamma$-carboxylation of the hepatic coagulation proteins.

When a single dose of MK-4, MK-7 or $\mathrm{K}_{1}(250 \mathrm{nmol} / \mathrm{kg}$ body weight) was administered to vitamin $\mathrm{K}$-deficient rats, the level of every K-vitamer, $\mathrm{K}_{1}$, MK-4 or MK-7, markedly increased in the liver but not in the femur. This suggests that intake of a larger amount of vitamin $\mathrm{K}$ is required for its accumulation in the femur than in the liver of rats. This is consistent with current views of different vitamin $\mathrm{K}$ requirements of liver and bone (Vermeer et al. 1995; Booth \& Suttie 1998). Since a smaller amount of vitamin $\mathrm{K}$ is sufficient for its accumulation in the liver than in the femur, abnormal blood coagulation hardly occurs. Therefore, it is possible that insufficient intake of vitamin $\mathrm{K}$ for longer periods will influence bone metabolism without affecting blood coagulation. Other explanations are also possible: (1) in the vitamin $\mathrm{K}$-deficiency state, the liver is capable of extracting vitamin $\mathrm{K}$ from the circulation at very high efficacy; or (2) bone tissue needs longer exposure to circulating vitamin $\mathrm{K}$ to be able to accumulate the vitamin in significant amounts.

We did not observe any changes in serum ucOC level in rats that were under strict vitamin K-deficient conditions for $17 \mathrm{~d}$. In human subjects, serum ucOC level is influenced by the intake of vitamin $\mathrm{K}$ for relatively short periods (Sokoll et al. 1997; Tsukamoto et al. 2000). Haffa et al. (2000) suggested that rats may be an inappropriate model for studying the effect of vitamin $\mathrm{K}$ on bone metabolism in human subjects, because they found that warfarin reduced bone OC level to only $0.65 \mu \mathrm{g} / \mathrm{mg}$, which was still much higher than that in healthy human subjects. Although serum ucOC level did not change, serum total OC level appeared to be slightly decreased by vitamin $\mathrm{K}$ deficiency (Fig. 3); this must be clarified in future studies.

Several researchers revealed that MK-4 is converted from $\mathrm{K}_{1}$ in liver, pancreas, salivary gland, kidney, brain, testis, heart and spleen (Thijssen \& Drittij-Reijnders, 1994; Yamamoto et al. 1997; Davidson et al. 1998; Ronden et al. 1998). The results obtained in the current study suggest that the conversion of $\mathrm{K}_{1}$ into MK-4 occurred also in the femur of rat because MK-4 was more abundant than $\mathrm{K}_{1}$ in the femur of the group administered $\mathrm{K}_{1}(1 \mathrm{mg} / \mathrm{kg}$ diet) for $17 \mathrm{~d}$ and MK-4 level was higher than that in vitamin K-deficient rats. Yamaguchi et al. (1999) reported that feeding of MK-7 to rats increased MK-4 level in the femur, indicating that MK-7 was converted into MK-4 in the femur. MK-4 enhances mineralization in human osteoblasts (Koshihara et al. 1992) and increases OC level in human osteoblasts in the presence of 1 1 ,25-dihydroxycholecalciferol (Koshihara et al. 1996); it also inhibits bone resorption in vitro (Hara et al. 1995). However, therapeutic treatment with MK-4 in osteoporotic patients did not have any effects on bone resorption markers (Shiraki et al. 2000). MK-4 may have some specific but as yet unknown functions in bone as well as other tissues.

PT was prolonged in vitamin $\mathrm{K}$-deficient rats. A single dose of a K-vitamer, $\mathrm{K}_{1}$, MK-4 or MK-7, shortened the 
prolonged PT and APTT. The effect of MK-7 lasted longer than that of MK-4 and $K_{1}$ on a molar basis. The longer acting effect of MK-7 was supported by the measurement of K-vitamers in the liver, in which the turnover of MK-7 was found to be delayed. The longer acting effect

(a)

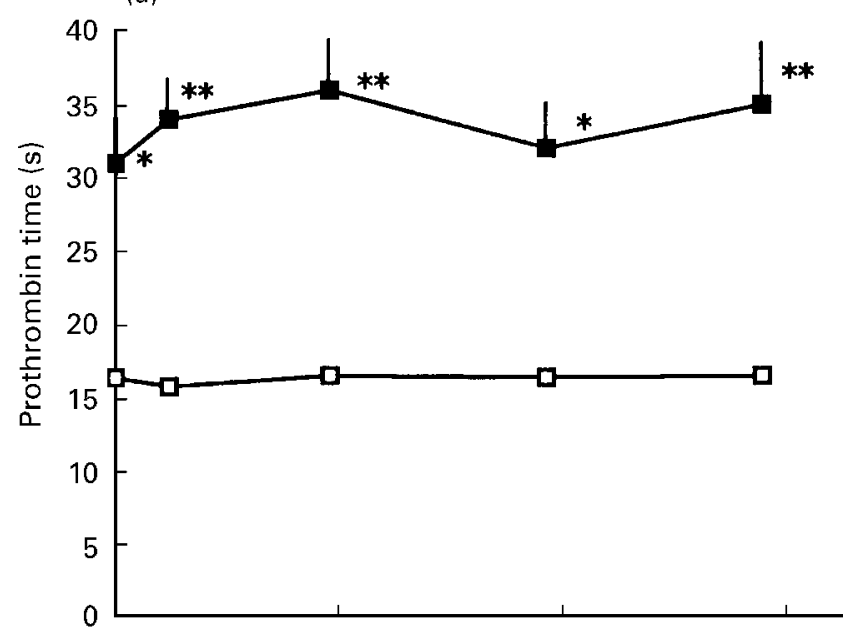

(b)

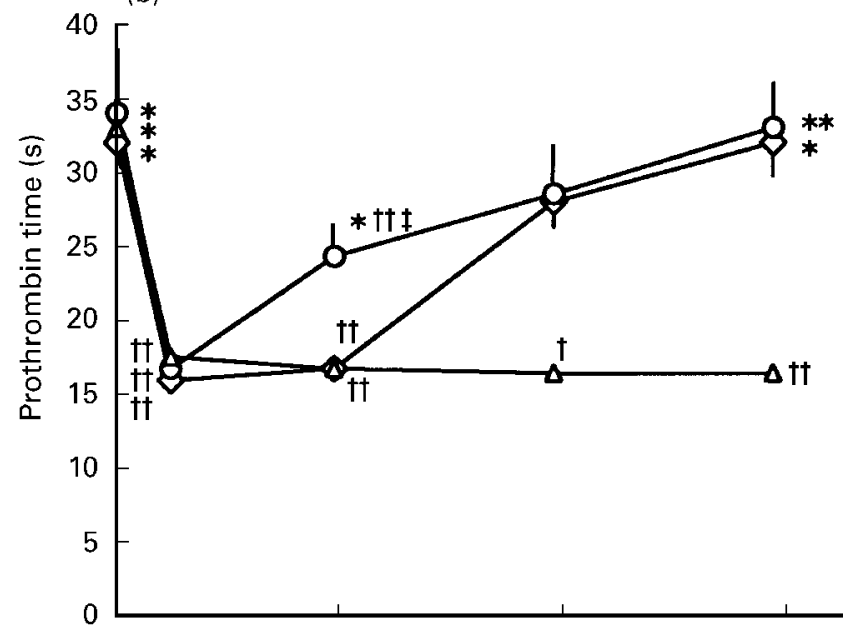

(c)

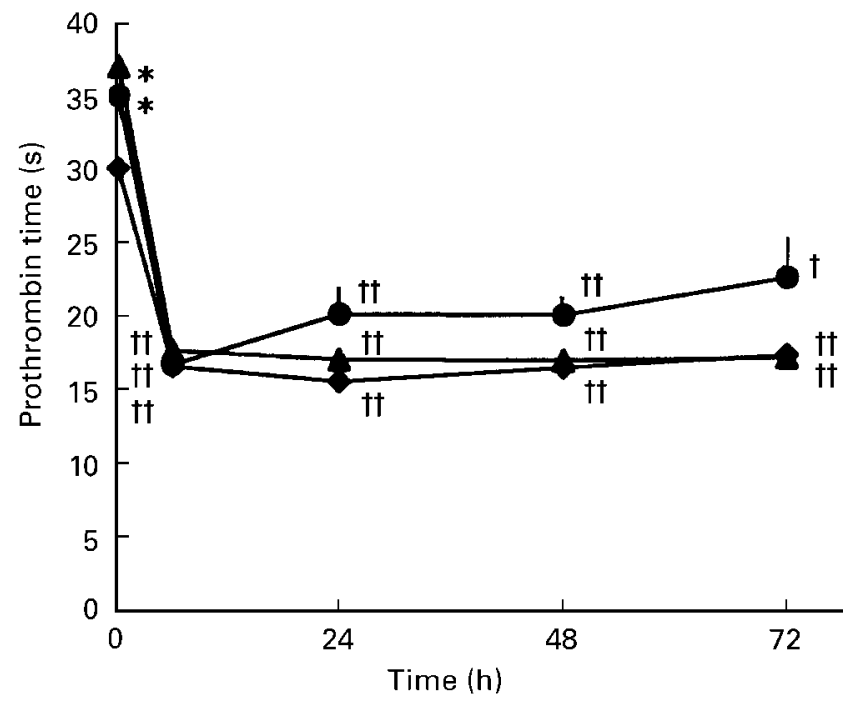

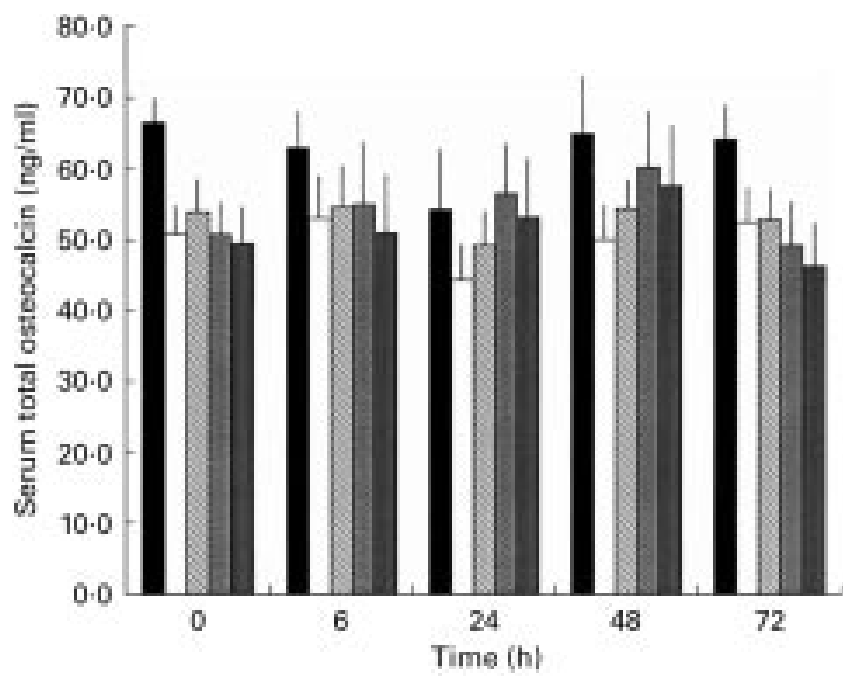

Fig. 3. Effect of a single dose of vitamin $\mathrm{K}$ on serum total osteocalcin level in vitamin K-deficient rats. Serum total osteocalcin levels were determined at $t 0,6,24,48$ and $72 \mathrm{~h}$ after a single-dose administration of phylloquinone $\left(\mathrm{K}_{1}\right)$, menoquinone (MK)-4 or MK-7 $(250 \mathrm{nmol} / \mathrm{kg}$ body weight). For details of diets and procedures, see

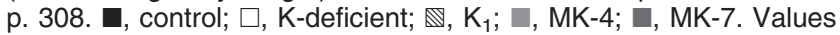
are means for five rats with standard errors shown by vertical bars.

of MK-7 on blood coagulation corresponded well with the report of Groenen-van Dooren et al. (1995), who showed that the stimulation of prothrombin synthesis by MK-9 lasts longer than that by $M K-4$ or $K_{1}$. Several other comparative studies on vitamin $\mathrm{K}$ activity, i.e. the ability to promote the $\gamma$-carboxylation of Gla-containing proteins in the liver by MK homologues, have been reported. MK-4, MK-5 and MK-6 have been shown to be highly effective in improving hypoprothrombinaemia in vitamin K-deficient rats induced by an anticoagulant (Akiyama et al. 1995). On the other hand, MK-7 was shown to have a much stronger effect on decreasing PIVKA-II (protein induced by vitamin $\mathrm{K}$ absence or antagonist II) than MK-4 in vitro (Nakanishi et al. 1989). Recently, Craciun et al. (1998) demonstrated that these discrepancies were due to the difference in the experimental model used. They suggested that the strong activity of MK-4 is only valid in rats treated with an anticoagulant. Although only limited amounts of MK- $n$ have been found in food, the most abundant homologues are MK-7, MK-8, and MK-9 (Sakano et al. 1988; Hirauchi et al.

Fig. 2. Effect of a single dose of vitamin $\mathrm{K}$ on prothrombin time in vitamin K-deficient rats. For details of diets and procedures, see $\mathrm{p}$. 308. (a) $\square$, vitamin-K-deficient control; $\square$, normal control fed $1 \mathrm{mg}$ phylloquinone $\left(\mathrm{K}_{1}\right) / \mathrm{kg}$ of diet. At $t 0$, the following doses of vitamin $\mathrm{K}$ were given to vitamin $\mathrm{K}$-deficient rats: (b) $50 \mathrm{nmol}$ each vitamer/kg body weight $\left(\diamond, \mathrm{K}_{1} ; \bigcirc\right.$, menaquinone (MK)-4; $\triangle$, MK-7); and (c) $250 \mathrm{nmol}$ each vitamer/kg body weight $\left(\bullet, \mathrm{K}_{1}\right.$; $\bullet$, MK-4; $\boldsymbol{\Delta}$, MK7). Values are means for five rats with standard errors shown by vertical bars. Mean values were significantly different from those of the control group: ${ }^{*} P<0.05,{ }^{* \star} P<0 \cdot 01$. Mean values were significantly different from those of the vitamin K-deficient group: $\dagger P<0.05, \dagger \dagger P<0.01$. Mean values were significantly different from those of the group given $50 \mathrm{nmol} \mathrm{K}_{1} / \mathrm{kg}$ body weight or MK-7-administered group: $\ddagger P<0.05$. 
1989; Shearer et al. 1996). The Japanese traditional food, natto, contains MK-7 at a high level and is a major source of vitamin $\mathrm{K}$ for the Japanese (Kaneki et al. 1995). In European studies, MK-7 and MK-8 were reported to be the predominant homologues of MK in human serum (Hodges et al. 1993a,b). It was thought that the bioavailability and the nutritional importance of $\mathrm{K}_{1}$ and various MK homologues with different side-chains should be evaluated in studies on human subjects.

In summary, we have shown that; (1) the turnover of vitamin $\mathrm{K}$ in the femur is slower than that in the liver; and (2) a larger amount of vitamin $\mathrm{K}$ is required for its accumulation in the femur than in the liver. Furthermore, the counteracting effect of MK-7 on the impaired blood coagulation mechanism in vitamin $\mathrm{K}$-deficient rats is much stronger than that of $\mathrm{K}_{1}$ or MK-4.

\section{Acknowledgement}

This work was supported by a grant from the Japanese Research and Development Association for New Functional Foods.

\section{References}

Akiyama Y, Hara K, Matsumoto A, Takahara S \& Tajima T (1995) Comparison of intestinal absorption of vitamin $\mathrm{K}_{2}$ (menaquinone) homologues and their effects on blood coagulation in rats with hypoprothrombinaemia. Biochemical Pharmacology 49, 1801-1807.

Barns RH \& Fiala G (1959) Effects of prevention of coprophagy in the rat. VI. Vitamin $\mathrm{K}_{1}$. Journal of Nutrition 68, 603-614.

Booth SL \& Suttie JW (1998) Dietary intake and adequacy of vitamin K. Journal of Nutrition 128, 785-788.

Collins MD \& Jones D (1981) Distribution of isoprenoid quinone structural types in bacteria and their taxonomic implications. Microbiological Review 45, 316-354.

Conly JM \& Stein K (1992) Quantitative and qualitative measurements of $\mathrm{K}$ vitamins in human intestinal contents. American Journal of Gastroenterology 87, 311-316.

Craciun AM, Groenen-van Dooren MMCL, Thijssen HHW \& Vermeer C (1998) Induction of prothrombin synthesis by $\mathrm{K}$-vitamins compared in vitamin K-deficient and in brodifacoum-treated rats. Biochimica et Biophysica Acta 1380, $75-81$.

Davidson RT, Foley AL, Engelle JA \& Suttie JW (1998) Conversion of dietary phylloquinone to tissue menaquinone- 4 in rats is not dependent on gut bacteria. Journal of Nutrition 128, 220-223.

Groenen-van Dooren MMCL, Ronden JE, Soute BAM \& Vermeer C (1993) The relative effects of phylloquinone and menaquinone on the blood coagulation factor synthesis in vitamin K-deficient rats. Biochemical Pharmacology 50, 797-801.

Groenen-van Dooren MMCL, Ronden JE, Soute BAM \& Vermeer C (1995) Bioavailability of phylloquinone and menaquinones after oral and colorectal administration in vitamin K-deficient rats. Biochemical Pharmacology 50, 797-801.

Haffa A, Krueger D, Bruner J, Engelke J, Gundberg C, Akhter M \& Binkley N (2000) Diet- or warfarin-induced vitamin K insufficiency elevates circulating undercarboxylated osteocalcin without altering skeletal status in growing female rats. Journal of Bone and Mineral Research 15, 872-878.

Hara K, Akiyama Y, Nakamura T, Murata S \& Morita I (1995)
The inhibitory effect of vitamin $\mathrm{K}_{2}$ (menatetrenone) on bone resorption may be related to its side chain. Bone 16, 179-184.

Hirauchi K, Sakano T, Notsumoto S, Nagaoka T, Morimoto A, Fujimoto K, Masuda S \& Suzuki Y (1989) Measurement of $\mathrm{K}$ vitamins in foods by high-performance liquid chromatography with fluorometric detection. Vitamins (Japan) 63, $147-151$.

Hodges SJ, Akesson K, Vergnaud P, Obrant K \& Delmas PD (1993a) Circulating levels of vitamins $K_{1}$ and $K_{2}$ decreased in elderly women with hip fracture. Journal Bone and Mineral Research 8, 1241-1245.

Hodges SJ, Bejui J, Leclercq M \& Delmas PD (1993b) Detection and measurement of vitamins $\mathrm{K}_{1}$ and $\mathrm{K}_{2}$ in human cortical and trabecular bone. Journal of Bone and Mineral Research 8 , 1005-1008.

Kaneki M, Mizuno Y, Hosoi T, Inoue S, Hoshino S, Akishita M, Akedo Y, Horiki K, Ouchi H \& Orimo H (1995) Taikouki-kotsusosyousyou niokeru kessei vitamin $\mathrm{K}$ noudo no kentou (Serum concentration of vitamin $\mathrm{K}$ in elderly women with involutional osteoporosis). Nihon Ronen Igaku Zasshi 32, $195-200$

Koshihara Y, Hoshi K, Ishibashi H \& Shiraki M (1996) Vitamin $\mathrm{K}_{2}$ promotes $1 \alpha, 25(\mathrm{OH})_{2}$ vitamin $\mathrm{D}_{3}$-induced mineralization in human periosteal osteoblasts. Calcified Tissue International 59, 466-473.

Koshihara Y, Hoshi K \& Shiraki M (1992) Enhancement of mineralization of human osteoblasts by vitamin $\mathrm{K}_{2}$ (menatetrenone). Journal of Clinical and Experimental Medicine 161, 439-440.

Mathers JC, Fernandes F, Hill MJ, McCarthy PT, Shearer MJ \& Oxley A (1990) Dietary modification of potential vitamin K supply from enteric bacterial menaquinones in rats. British Journal of Nutrition 63, 639-652.

Merle B \& Delmas PD (1990) Normal carboxylation of circulating osteocalcin (bone Gla protein) in Paget's disease of bone. Bone and Mineral 11, 237-245.

Nakanishi T, Furukawa M, Okuda H, Iizuka B \& Obata H (1989) Comparison of effects of menaquinone-4 and menaquinone-7 assessed by decrease of PIVKA-II levels in human hepatoma cells in culture. Vitamins (Japan) 63, 253-257.

Poser JW \& Price PA (1978) A method for decarboxylation of $\gamma$ carboxyglutamic acid in proteins. Journal of Biological Chemistry 254, 431-436.

Price PA (1985) Vitamin K-dependent formation of bone gla protein (osteocalcin) and its function. Vitamins and Hormones $\mathbf{4 2}$, $65-108$.

Ronden JE, Drittij-Reijnders MJ, Vermeer C \& Thijssen HH (1998) Intestinal flora is not an intermediate in the phylloquinone-menaquinone-4 conversion in the rat. Biochimica et Biophysica Acta 1379, 69-75.

Sakano T, Notsumoto S, Nagaoka T, Morimoto A, Fujimoto K, Masuda S, Suzuki Y \& Hirauchi K (1998) Measurement of K vitamins in food by high performance liquid chromatography with fluorometric detection. Vitamins (Japan) 62, 393-398.

Sato T, Yamada Y, Ohtani Y, Mitsui N, Murasawa H \& Araki S (2001) Production of menaquinone (vitamin $\mathrm{K}_{2}$ )-7 by Bacillus subtilis. Journal of Bioscience and Bioengineering 91, 16-21.

Shearer MJ (1990) Vitamin K and vitamin K-dependent proteins. British Journal of Haematology 75, 156-162.

Shearer MJ, Bach A \& Kohlemeier M (1996) Chemistry, nutritional source, tissue distribution and metabolism of vitamin K with special reference to bone health. Journal of Nutrition 126, Suppl., 1181S-1186S.

Shiraki M, Shiraki Y, Aoki C \& Miura M (2000) Vitamin $\mathrm{K}_{2}$ (menatetrenone) effectively prevents fractures and sustains lumbar bone mineral density in osteoporosis. Journal of Bone and Mineral Research 15, 515-521. 
Sokoll JJ, Booth SL, O'Brien ME, Davidson KW, Tsaioun KI \& Sadowski JA (1997) Changes in serum osteocalcin, plasma phylloquinone, urinary $\gamma$-carboxyglutamic acid in response to altered intakes of dietary phylloquinone in human subjects. American Journal of Clinical Nutrition 65, 779-784.

Suttie JW (1995) The importance of menaquinones in human nutrition. Annual Reviews of Nutrition 15, 399-417.

Szulc P, Arlot M, Chapuy M-C, Duboeuf F, Meunier PJ \& Desmas PD (1994) Serum undercarboxylated osteocalcin correlates with hip bone mineral density in elderly women. Journal of Bone and Mineral Research 9, 1591-1595.

Szulc P, Chapuy M-C, Meunier PJ \& Delmas PD (1993) Serum undercarboxylated osteocalcin is a marker of the hip fracture in elderly women. Journal of Clinical Investigation 91, 1769-1774.

Thijssen HHW \& Drittij-Reijnders MJ (1994) Vitamin K distribution in rat tissues: dietary phylloquinone is a source of tissue menaquinone-4. British Journal of Nutrition 72, $415-425$.
Tsukamoto Y, Ichise H, Kakuda H \& Yamaguchi M (2000) Intake of fermented soybean (natto) increases circulating vitamin $\mathrm{K}_{2}$ (menaquinone-7) and $\gamma$-carboxylated osteocalcin concentration in normal individuals. Journal of Bone and Mineral Metabolism 18, 216-222.

Uchida K, Nomura Y, Takase H, Harauchi T, Yoshizaki T \& Nakao H (1986) Effects of vitamin K-deficient diets and fasting on blood coagulation factors in conventional and germfree rats. Japan Journal of Pharmacology 40, 115-122.

Vermeer C, Jie K-SG \& Knapen MHJ (1995) Role of vitamin K in bone metabolism. Annual Reviews of Nutrition 15, 1-22.

Yamaguchi M, Taguchi H, Gao YH, Igasshi A \& Tsukamoto Y (1999) Effect of vitamin $K_{2}$ (menaquinone-7) in fermented soybean (natto) on bone loss in ovariectomized rats. Journal of Bone and Mineral Metabolism 17, 23-29.

Yamamoto R, Komai M, Kojima K, Furukawa Y \& Kimura S (1997) Menaquinone-4 accumulation in various tissues after an oral administration of phylloquinone in Wistar rats. Journal of Nutritional Science and Vitaminology (Tokyo) 42, 133-143. 